\section{(6) OPEN ACCESS}

\title{
Cost-effectiveness of eplerenone in patients with systolic heart failure and mild symptoms
}

\author{
Dawn Lee, ${ }^{1}$ Koo Wilson, ${ }^{2}$ Ron Akehurst, ${ }^{1}$ Martin R Cowie, ${ }^{3}$ Faiez Zannad, ${ }^{4}$ \\ Henry Krum, ${ }^{5}$ Dirk J van Veldhuisen, ${ }^{6}$ John Vincent, ${ }^{7}$ Bertram Pitt, ${ }^{8}$ \\ John J V McMurray, ${ }^{9}$ for the Eplerenone in Mild Patients Hospitalization \\ And Survival Study in Heart Failure (EMPHASIS-HF) Study
}

- Additional material is published online only. To view please visit the journal online (http://dx.doi.org/10.1136/ heartjnl-2014-305673).

For numbered affiliations see end of article.

\section{Correspondence to} Dawn Lee, BresMed, North Church House, 84 Queen St, Sheffield S1 2DW, UK: dlee@bresmed.co.uk

Received 14 February 2014 Revised 1 June 2014 Accepted 3 June 2014 Published Online First 3 July 2014

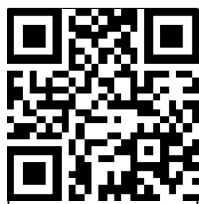

\section{ABSTRACT}

Aim In the Eplerenone in Mild Patients Hospitalization and Survival Study in Heart Failure (EMPHASIS-HF), aldosterone blockade with eplerenone decreased mortality and hospitalisation in patients with mild symptoms (New York Heart Association class II) and chronic systolic heart failure (HF). The present study evaluated the cost-effectiveness of eplerenone in the treatment of these patients in the UK and Spain.

Methods and results Results from the EMPHASIS-HF trial were used to develop a discrete-event simulation model estimating lifetime direct costs and effects (life years and quality-adjusted life years (QALYS) gained) of the addition of eplerenone to standard care among patients with chronic systolic HF and mild symptoms. Eplerenone plus standard care compared with standard care alone increased lifetime direct costs per patient by £4284 for the UK and $€ 7358$ for Spain, with additional quality-adjusted life expectancy of 1.22 QALYs for the UK and 1.33 QALYs for Spain. Mean lifetime costs were £3520 per QALY in the UK and $€ 5532$ per QALY in Spain. Probabilistic sensitivity analysis suggested a 100\% likelihood of eplerenone being regarded as cost-effective at a willingness-to-pay threshold of $€ 20000$ per QALY (UK) or $€ 30000$ per QALY (Spain).

Conclusions By currently accepted standards of value for money, the addition of eplerenone to optimal medical therapy for patients with chronic systolic HF and mild symptoms is likely to be cost-effective.

\section{INTRODUCTION}

Around $1 \%-2 \%$ of adults in Europe have heart failure (HF) which causes an immense symptom burden due to breathlessness, fatigue and oedema, greatly reduces quality of life and is a leading cause of hospital admission and, therefore, healthcare expenditure. ${ }^{12}$ Mortality within 12 months of a HF hospital admission is $30 \%-40 \%$, rising to a 5 -year mortality rate of $50 \%-75 \% .^{34}$

The primary goals of the treatment of HF are, therefore, to relieve symptoms, reduce the rate of hospitalisation and improve survival. ${ }^{5}$ ACE inhibitors and $\beta$-blockers have been shown to achieve these goals in patients with $\mathrm{HF}$ and reduced EF (HF-REF), irrespective of symptom severity (New York Heart Association (NYHA) class II-IV), and are thus strongly recommended (class I, evidence level A) in clinical guidelines on the basis of multiple clinical trials. ${ }^{5}$
Until recently, mineralocorticoid receptor antagonists (MRAs) were recommended (class I, evidence level B) only in patients with moderate-to-severe symptoms (NYHA class III or IV) on the basis of the Randomized Aldactone Evaluation Study (RALES). ${ }^{6}$ This recommendation has now been strengthened (class I, evidence level A) and broadened (to include all patients with symptomatic HF-REF) following the Eplerenone in Mild patients Hospitalization and Survival Study in Heart Failure (EMPHASIS-HF), which showed a reduction in mortality and all-cause hospitalisation when an MRA was added to optimal evidence-based therapy in patients with mild symptoms (NYHA class II HF), LVEF $\leq 30 \%$ (or, if $>30 \%-35 \%$, a QRS duration of $>130 \mathrm{~ms}$ on electrocardiography) and recent hospitalisation for a cardiovascular (CV) reason, elevated plasma B-type natriuretic peptide (BNP) or N-terminal pro-BNP. ${ }^{7}$ These findings are supported by a further trial, the Eplerenone Post-Acute Myocardial Infarction Heart Failure Efficacy and Survival Study (EPHESUS), in patients with myocardial infarction complicated by left ventricular systolic dysfunction and $\mathrm{HF}^{8}$

We have evaluated the cost-effectiveness of eplerenone in patients with HF-REF and mild symptoms (NYHA class II) because, beside efficacy and safety, the adoption of new treatments is also influenced by whether the added value is worth the added cost. We have done this from the perspective of two European countries, the UK and Spain.

\section{METHODS}

\section{Model description}

A discrete-event simulation model was developed to project the rates and times of important clinical events and assign to these lifetime costs and quality-of-life consequences (figure 1). Two treatment pathways were simulated, in line with the trial protocol: standard therapy with the addition of eplerenone (starting dose of $25 \mathrm{mg}$ once daily; at 4 weeks, increased to $50 \mathrm{mg}$ once daily) and standard therapy with no additional active treatment (standard care). Model outputs are presented in terms of mean life expectancy, quality-adjusted life expectancy, direct costs and incremental costeffectiveness ratios (ICERs).

The simulated patient population in the model was derived from that enrolled in EMPHASIS-HF.? All patients were in NYHA class II, with a mean 
Figure 1 Model structure. CV, cardiovascular; HF, heart failure; QALY, quality-adjusted life year.

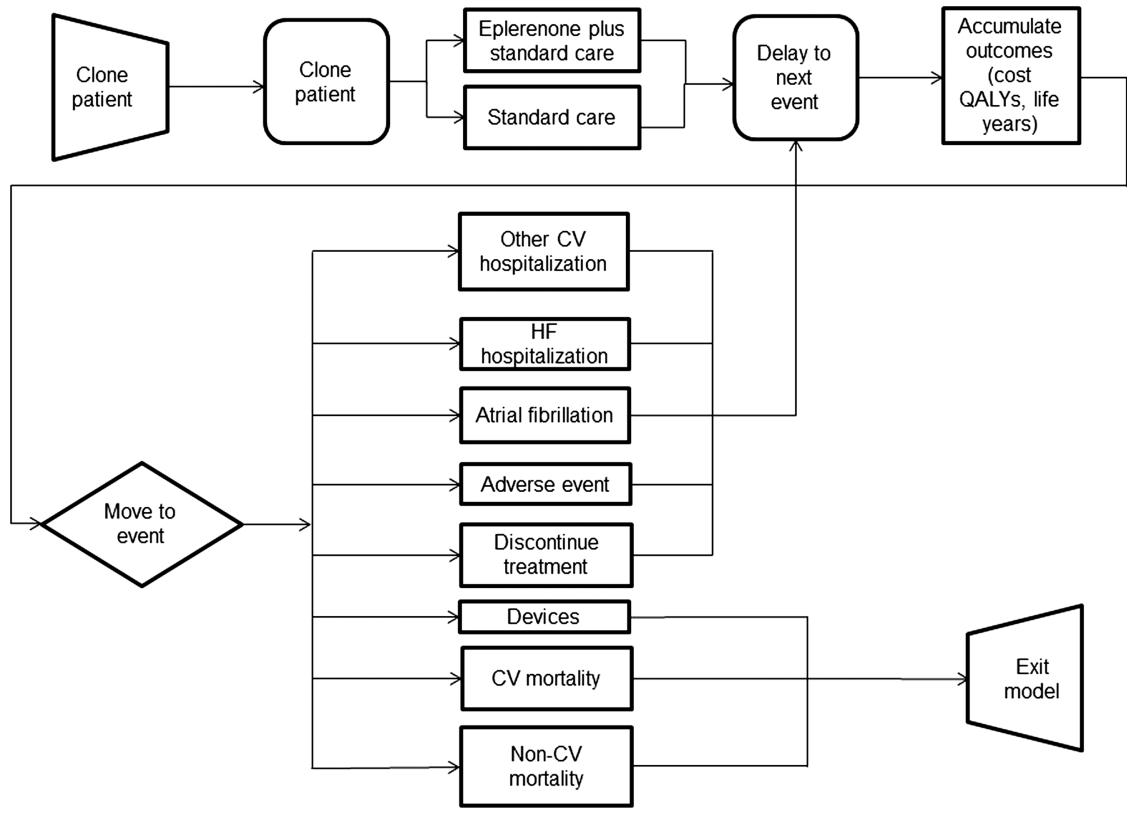

age of 69 , had a mean LVEF of $26 \%$ and $78 \%$ of patients were men. Only concomitant medication usage at enrolment was reported in the trial and so it was assumed subjects remained on the same medication for their lifetimes.

A discrete-event simulation models time to clinically and economically meaningful events on the basis of individuallysimulated patients. This method was chosen in preference to a Markov model as it is possible to model an unlimited number of events for each patient and make the probability of events contingent on time, the number and type of events the patient has already experienced, and the patient's characteristics (such as age). ${ }^{9}$

Patient-level data from EMPHASIS-HF were used to determine risk equations for each event by fitting a distribution to the time to each event. Treatment effectiveness was captured in the model by tracking progress to the following health states reported in the trial: HF hospitalisation, other CV hospitalisation, new-onset atrial fibrillation, implantation of cardiac resynchronisation therapy (CRT) or implantable cardioverterdefibrillator (ICD) devices, adverse events, discontinuation of eplerenone, CV mortality, and non-CV mortality.

The adverse events included within the model are the key events reported in EMPHASIS-HF: hyperkalaemia, hypokalaemia, renal failure, hypotension and gynaecomastia. ${ }^{7}$ New-onset diabetes, heart transplants, dialysis and kidney transplants were not included in the model because the rates were low and either similar or the same for both trial arms, meaning that inclusion would not change the model results. ${ }^{10}$ In addition, consideration was given to modelling the change in NYHA class as time progressed, but as there was no significant change in NYHA class between the two arms $(p=0.14)$, the majority of patients remained in class II ( $\geq 75 \%$ of patients at all time points up to month 42 were in NYHA class on both arms) and available evidence to extrapolate beyond the trial is limited, this was not included. This implies that the reported benefits of eplerenone are instead based upon the reduction in mortality, hospitalisations and new-onset atrial fibrillation.

Figure 1 provides an overview of the model flow. In brief, simulated patients were created and individual times to events were randomly assigned to them based upon the risk equations for each model event (see online supplementary appendix), derived from EMPHASIS-HF data for each arm separately, except non-CV mortality which was assumed to be the same for eplerenone and standard care. Each patient was then copied and the two identical patients were assigned to treatment with either standard care or eplerenone plus standard care. order to minimise stochastic error and provide an appropriate level of certainty in the ICER (SD in the ICER over repeated simulations $<£ 100(€ 120))$.

At the start of the model, patient's times to event were simulated and the patient progressed to the first event to occur. Following the event there were two possible options:

1. The patient exited the model if:

A. death occurred

B. an ICD or CRT device was implanted: remaining life years, costs and quality-adjusted life years (QALYs) were assigned to patients at this point based upon an assessment conducted for the National Institute of Health and Care Excellence on the effectiveness of these devices; ${ }^{11}$ the EMPHASIS trial information was not sufficient to estimate device effect due to lack of sufficient follow-up post device implantation.

2. The patient remained in the model and the time to the next event was calculated.

If the event was deemed to influence the time of other events, the times to these events were recalculated. Events that were deemed to interact in this way were: HF (and other CV) hospitalisations, which increase the likelihood of both CV mortality and repeat hospitalisations, and adverse events, which increase the likelihood of future adverse events.

Parametric survival models (Weibull, exponential and lognormal) were tested and the best fitting models used to describe time-to-event. Similar parametric models were fitted where necessary to outcomes with multiple events following the method recommended by Harrell. ${ }^{12}$

Patients were followed over the course of the simulation with their characteristics updated over time. It was assumed that patients who discontinued treatment (after a hospitalisation or adverse event) with eplerenone returned to standard care. Patient discontinuation rates were based on the EMPHASIS-HF data.
The model simulated 25000 patients for each treatment in 
It should be noted that the clinical data used in the model included recurrent events and not just the first events reported in the main results paper from EMPHASIS-HF. ${ }^{7} 13$

A scenario is included where patients only exit the model on death, and devices are not included within the model, to test the sensitivity of the results.

In the base-case analysis, a lifetime horizon was chosen to fully capture the costs and quality-of-life benefits resulting from treatment with eplerenone given the increased survival. There were no modelled differences between the two countries in the standard-treatment practices or the comparators. The model implementation used Simul8 15.0 and Microsoft Excel 2010.

All cost, quality-of-life and length-of-life outcomes were discounted at 3.5\% annually within the UK model and 3.0\% annually within the Spanish model, in line with their national reimbursement reference cases.

\section{Costs and perspective}

Cost inputs for the model are given in table 1. Only initial acute event costs were accounted for when hospitalisations occurred. No data were available to estimate the direct costs of death, and these were not included in the model. This is a conservative assumption.

The costs for other CV hospitalisations, adverse events and devices were based on the proportion of patients from the EMPHASIS-HF trial experiencing each subcategory of event. The cost of each adverse event is higher on the standard care arm compared with the eplerenone arm; the types of events experienced are different and a higher proportion of patients experiencing adverse events required hospitalisation (23\% of adverse events experienced by patients on the standard care arm required hospitalisation compared with $15 \%$ on the eplerenone arm). When a patient was fitted with a device, costs were applied for fitting of the device and each pulse generator replacement that would be required for the patient's remaining life span.

Data on prescribed medication were taken from the trial publication and a weighted average of concomitant medications (excluding eplerenone) calculated to account for medication resource usage. Eplerenone was assumed to be prescribed for a patient's lifetime or until discontinuation.

The cost of two hospital visits and sets of blood chemistry tests is included on initiation of treatment with eplerenone. Thereafter, annual disease management and monitoring costs are assumed to be the same for standard care and treatment with eplerenone.

\section{Quality of life}

Quality of life was calculated using the utility formula from Göhler et $a l^{14}$ using the baseline characteristics of the patients in the EMPHASIS-HF trial. Utility decrements were assigned to patients as they experienced events. The utility values used within the model are summarised in table 1 .

\section{Sensitivity analysis}

A range of deterministic sensitivity analyses were carried out to test the robustness of the model projections by varying key inputs and assumptions. One-way parameter sensitivity analyses were performed by varying each parameter within its likely range

Table 1 Utilities and medication and event costs used within the model

\begin{tabular}{|c|c|c|c|}
\hline Parameter & Input value-UK model & Input value-Spanish model & Reference \\
\hline \multicolumn{4}{|l|}{ Per annum treatment costs } \\
\hline Eplerenone drug costs & f557 & $€ 1086$ & 2324 \\
\hline Standard care drug costs & f0 & $€ 0$ & \multirow{2}{*}{$\begin{array}{l}\text { Assumed } \\
2324\end{array}$} \\
\hline Concomitant medications & $£ 229$ & $€ 290$ & \\
\hline Eplerenone treatment initiation (one-off)* & 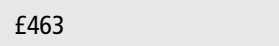 & $€ 119$ & $25-27$ \\
\hline Disease management and monitoring & $£ 443$ & $€ 60$ & $25-27$ \\
\hline \multicolumn{4}{|l|}{ Event-based costs } \\
\hline HF hospitalisation & $£ 3463$ & $€ 3321$ & 2527 \\
\hline Other CV hospitalisation & f3001 & $€ 4980$ & 2527 \\
\hline Adverse event-eplerenonet & $£ 237$ & $€ 786$ & 2527 \\
\hline Adverse event—-standard caret & $£ 280$ & $€ 1133$ & 2527 \\
\hline Cost of CRT and ICD devices & $£ 5842$ & $€ 9005$ & 2527 \\
\hline Average CRT and ICD device life & 5.8 years & 5.8 years & 11 \\
\hline \multicolumn{4}{|l|}{ Quality-of-life utilities } \\
\hline Baseline utility & 0.84 & 0.84 & 14 \\
\hline Utility decrement for patients who experience one hospitalisation & -0.024 & -0.024 & 14 \\
\hline Utility decrement for patients who experience two hospitalisations & -0.031 & -0.031 & 14 \\
\hline Utility decrement for patients who experience three hospitalisations & -0.055 & -0.055 & 14 \\
\hline Utility decrement for new-onset atrial fibrillation & -0.084 & -0.084 & 28 \\
\hline Lifetime utility decrement for adverse events-eplerenone & -0.0003 & -0.0003 & 19 \\
\hline Lifetime utility decrement for adverse events-standard care & -0.0001 & -0.0001 & 19 \\
\hline Short-term utility decrement for adverse events—eplerenoneł & -0.0012 & -0.0012 & 1929 \\
\hline Short-term utility decrement for adverse events—-standard careł & -0.0008 & -0.0008 & 19 \\
\hline \multicolumn{4}{|c|}{$\begin{array}{l}\text { *Two hospital appointments with a consultant and two sets of blood chemistry tests. } \\
\text { tThe unit costs of the adverse events for each of the five events modelled for the two arms were assumed to be the same. The proportion of patients experiencing each type of event } \\
\text { (hospitalised and non-hospitalised) was calculated using the trial results. Costs are higher on the placebo arm as more patients were hospitalised ( } 23 \% \text { of adverse events vs } 15 \%) \text { and } \\
\text { more patients experienced renal failure which is the most costly of the five key adverse events included. } \\
\text { ¥Applied for } 21 \text { days based upon clinician advice. } \\
\text { CRT, cardiac resynchronisation therapy; CV, cardiovascular; HF, heart failure; ICD, implantable cardioverter-defibrillator. }\end{array}$} \\
\hline
\end{tabular}



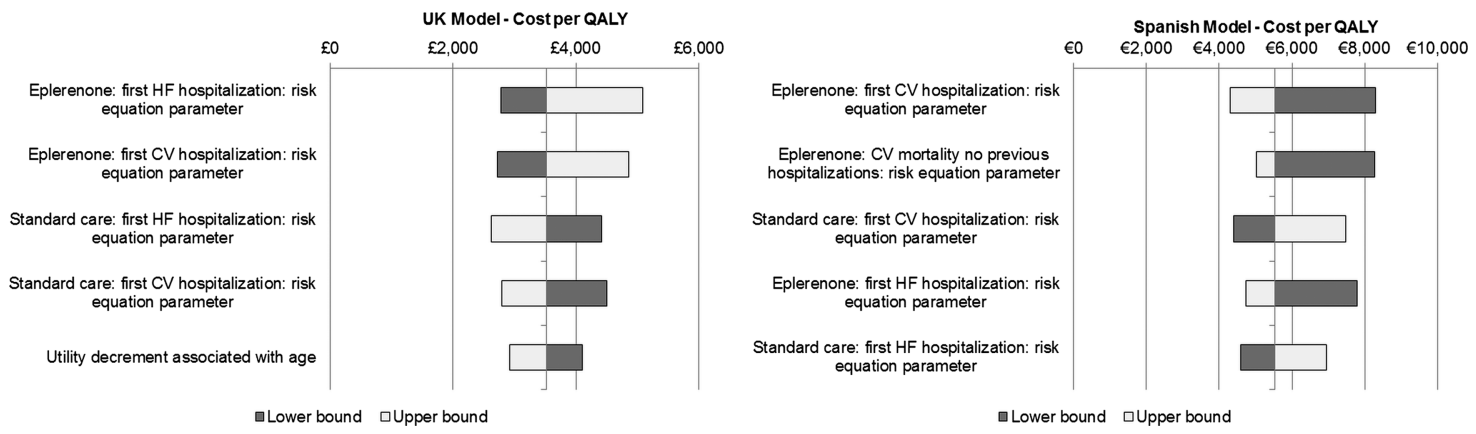

Figure 2 Deterministic sensitivity analysis tornado plots. CV, cardiovascular; HF, heart failure; QALY, quality-adjusted life year.

using the $95 \%$ CIs of the parameter distributions (figure 2). In addition, a range of scenario analyses were conducted.

A probabilistic sensitivity analysis (PSA) was also performed, producing 100 pairs of incremental effectiveness and cost results. These were plotted on a cost-effectiveness plane to illustrate the probability of being cost-effective for both countries' willingness-to-pay (WTP) thresholds (figure 3).

\section{RESULTS}

The results of the base-case analysis projected lifetime improvements in clinical outcomes with increased costs for subjects receiving eplerenone in addition to standard care compared with standard care alone and are shown in table 2.

Over a patient's lifetime, there were higher costs associated with eplerenone than standard care. The increases in costs produced by the model were $£ 4284$ for the UK and $€ 7358$ for Spain. The main differences in costs between the two countries were due to the cost of eplerenone (which is higher in Spain than the UK) and the costs of disease management and monitoring (which are higher in the UK).

Over a patient's lifetime, the mean quality-adjusted life expectancy for eplerenone using a discount rate of 3.5\% (UK simulation) was 6.19 versus 4.98 QALYs for standard care (a difference of 1.22 QALYs). There was a larger improvement in absolute discounted life expectancy: 7.74 versus 6.23 years for eplerenone and standard care, respectively.

Using a discount rate of 3\% (Spanish simulation), the mean quality-adjusted life expectancy was 6.53 versus 5.20 QALYs for eplerenone and standard care, respectively (a difference of 1.33 QALYs). There was a larger improvement in absolute discounted life expectancy: 8.18 versus 6.52 years for eplerenone and standard care, respectively. These outcomes produced ICERs of $£ 3520$ per QALY for the UK and $€ 5532$ for Spain.

The results of the deterministic sensitivity analyses are presented in figure 2. In all cases, the ICER remains below $£ 5500$
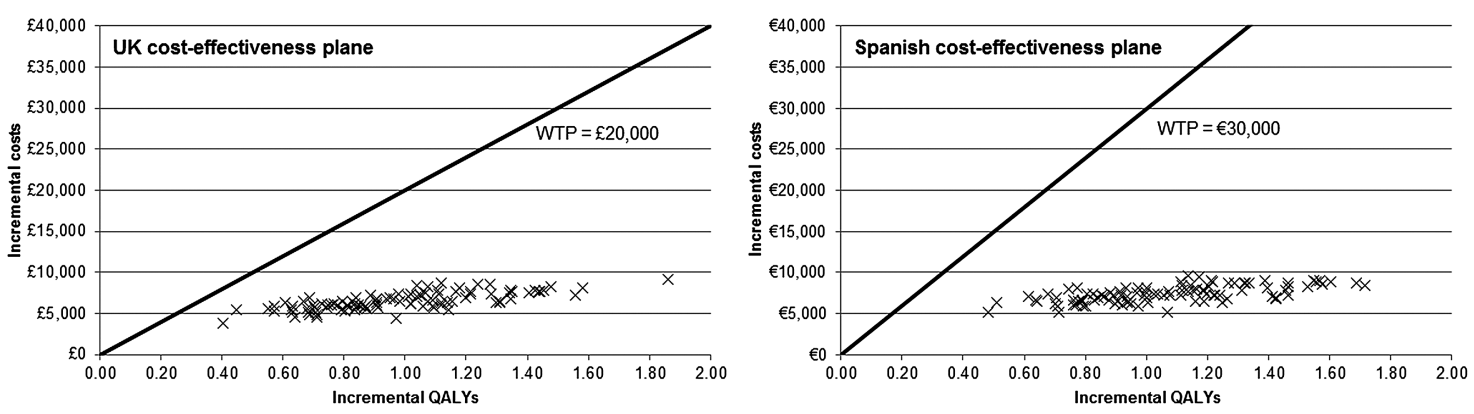

Figure 3 Incremental quality-adjusted life expectancy and lifetime costs. QALY, quality-adjusted life year; WTP, willingness-to-pay threshold. per QALY in the UK model and below $€ 8500$ per QALY in the Spanish model, indicating that the model is very stable in its predictions and not sensitive to any one parameter. These ICERs are well below the accepted WTP thresholds in both of these countries ( $£ 20-30000$ per QALY in the UK and $€ 30000$ per QALY in Spain).

Results from scenario analyses are presented in table 3 and show that the ICER remains approximately equal to the accepted WTP thresholds in both countries even when the EMPHASIS-HF data are used with no extrapolation at all. The model results are not sensitive to either the utility decrements applied for events or the rates of device implantation. The ICER improves as the modelled time horizon increases because longer time horizons allow for more time for the modelled benefits of eplerenone to be realised.

The mean results of the PSA are very similar to the deterministic base case described above. When incorporating the uncertainty around all model inputs, the 100 simulations gave an overall mean ICER of $£ 6939$ (95\% Bayesian credibility interval (£6656; £7222)) for the UK model and $€ 7217$ (95\% Bayesian credibility interval (€6905; €7528)) for the Spanish model.

Scatter plots of the 100 pairs of incremental quality-adjusted life expectancies and lifetime costs are presented in figure 3. In all cases, eplerenone provides a QALY benefit over standard care and the values simulated fall below the $£ 20000$ WTP threshold within the UK model and below the $€ 30000$ threshold within the Spanish model, showing that eplerenone is consistently cost-effective.

\section{DISCUSSION}

Based upon the EMPHASIS-HF trial, this modelling analysis shows that the use of eplerenone in patients with HF-REF and mild symptoms reduced hospitalisations (particularly HF hospitalisations) and the costs associated with these. These savings partially offset the additional cost of eplerenone treatment (and 
Table 2 Base-case scenario results from the discrete-event simulation model

\begin{tabular}{|c|c|c|c|c|c|c|}
\hline & \multicolumn{3}{|l|}{ UK } & \multicolumn{3}{|l|}{ Spain } \\
\hline & Eplerenone & Standard care & Difference & Eplerenone & Standard care & Difference \\
\hline Other CV hospitalisations & 1.27 & 1.23 & 0.04 & As UK & & \\
\hline HF hospitalisations & 1.32 & 1.60 & -0.28 & & & \\
\hline Diagnosis of atrial fibrillation & 0.09 & 0.12 & -0.03 & & & \\
\hline CV mortality & 0.71 & 0.77 & -0.05 & & & \\
\hline Non-CV mortality & 0.08 & 0.06 & 0.02 & & & \\
\hline Adverse events & 0.67 & 0.43 & 0.24 & & & \\
\hline ICD or CRT & 0.59 & 0.46 & 0.13 & & & \\
\hline Discontinuation of eplerenone & 0.42 & - & 0.42 & & & \\
\hline Cost of CV hospitalisations & £3236 & $£ 3240$ & $-£ 4$ & $€ 5493$ & $€ 5478$ & $€ 15$ \\
\hline Cost of HF hospitalisations & f3888 & f4862 & $-£ 973$ & $€ 3815$ & $€ 4748$ & $-€ 932$ \\
\hline Cost of active treatment & f3873 & f0 & £3873 & $€ 7080$ & $€ 0$ & $€ 7080$ \\
\hline Cost of concomitant treatment & $£ 1773^{*}$ & $£ 1426$ & f347 & $€ 2371$ & $€ 1889$ & $€ 481$ \\
\hline Cost of devices & f3597* & $£ 3046$ & f551 & $€ 3641$ & $€ 3048$ & $€ 592$ \\
\hline Cost of disease management and monitoring & f3433* & $£ 2761$ & $\mathrm{f} 672$ & $€ 488$ & $€ 389$ & $€ 99$ \\
\hline Cost of adverse events & £137 & f108 & $\mathrm{f} 30$ & $€ 465$ & $€ 443$ & $€ 22$ \\
\hline Total cost & f18 559 & $£ 14275$ & $£ 4284$ & $€ 23353$ & $€ 15995$ & $€ 7358$ \\
\hline Total QALYs & 6.19 & 4.98 & 1.22 & 6.53 & 5.20 & 1.33 \\
\hline Total life years & 7.74 & 6.23 & 1.52 & 8.18 & 6.52 & 1.66 \\
\hline ICER & £3520 & & & $€ 5532$ & & \\
\hline Cost per life year gained & f2825 & & & $€ 4431$ & & \\
\hline
\end{tabular}

*While the rate of use of devices, management and monitoring, and concomitant treatment requirements is either the same for the two arms or lower on the eplerenone arm, as patients are expected to live longer, the total cost over a patient's lifetime is higher.

CRT, cardiac resynchronisation therapy; CV, cardiovascular; HF, heart failure; ICD, implantable cardioverter-defibrillator; ICER, incremental cost-effectiveness ratio; QALY, quality-adjusted life year.

extension of life) resulting in very modest ICERs of $£ 3520$ and $€ 5532$ per QALY gained for eplerenone versus standard care in the UK and Spain, respectively. These ICERs are much lower than the $£ 20000$ WTP threshold in the UK and the $€ 30000$ threshold in Spain, indicating that eplerenone, as an add-on therapy in the treatment of HF-REF with mild symptoms (NYHA class II), represents a cost-effective option, generating additional clinical benefit at an acceptable incremental cost in both countries. The results were robust to deterministic and probabilistic sensitivity analyses.

Table 3 Scenario analysis results from the discrete-event simulation model

\begin{tabular}{|c|c|c|c|c|}
\hline Scenario & Country & $\begin{array}{l}\text { Incremental } \\
\text { costs }\end{array}$ & $\begin{array}{l}\text { Incremental } \\
\text { QALYs }\end{array}$ & ICER \\
\hline $\begin{array}{l}\text { Using EMPHASIS-HF } \\
\text { data with no } \\
\text { extrapolation }\end{array}$ & $\begin{array}{l}\text { UK } \\
\text { Spain }\end{array}$ & $\begin{array}{l}£ 940 \\
€ 1427\end{array}$ & $\begin{array}{l}0.05 \\
0.05\end{array}$ & $\begin{array}{l}€ 20730 \\
€ 31138\end{array}$ \\
\hline $\begin{array}{l}\text { Time horizon } \\
2 \text { years }\end{array}$ & $\begin{array}{l}\text { UK } \\
\text { Spain }\end{array}$ & $\begin{array}{l}£ 717 \\
€ 1157\end{array}$ & $\begin{array}{l}0.04 \\
0.04\end{array}$ & $\begin{array}{l}€ 20101 \\
€ 32208\end{array}$ \\
\hline $\begin{array}{l}\text { Time horizon } \\
5 \text { years }\end{array}$ & $\begin{array}{l}\text { UK } \\
\text { Spain }\end{array}$ & $\begin{array}{l}€ 1160 \\
€ 2340\end{array}$ & $\begin{array}{l}0.19 \\
0.20\end{array}$ & $\begin{array}{l}£ 6016 \\
€ 11932\end{array}$ \\
\hline $\begin{array}{l}\text { No utility decrement } \\
\text { for adverse events, } \\
\text { atrial fibrillation or } \\
\text { hospitalisations }\end{array}$ & $\begin{array}{l}\text { UK } \\
\text { Spain }\end{array}$ & $\begin{array}{l}€ 4284 \\
€ 7358\end{array}$ & $\begin{array}{l}1.20 \\
1.32\end{array}$ & $\begin{array}{l}€ 3558 \\
€ 5584\end{array}$ \\
\hline $\begin{array}{l}\text { Increased use of } \\
\text { devices }\end{array}$ & $\begin{array}{l}\text { UK } \\
\text { Spain }\end{array}$ & $\begin{array}{l}£ 4495 \\
€ 7396\end{array}$ & $\begin{array}{l}1.22 \\
1.33\end{array}$ & $\begin{array}{l}€ 3693 \\
€ 5560\end{array}$ \\
\hline No use of devices & $\begin{array}{l}\text { UK } \\
\text { Spain }\end{array}$ & $\begin{array}{l}€ 3440 \\
€ 5223\end{array}$ & $\begin{array}{l}1.23 \\
1.34\end{array}$ & $\begin{array}{l}£ 2802 \\
€ 3893\end{array}$ \\
\hline
\end{tabular}

EMPHASIS-HF, Eplerenone in Mild Patients Hospitalization and Survival Study in Heart

Failure; ICER, incremental cost-effectiveness ratio; QALY, quality-adjusted life year.
Our findings are in keeping with the favourable costeffectiveness of other disease-modifying therapies in HF-REF, including ACE inhibitors, angiotensin receptor blockers and B-blockers. ${ }^{15-18}$ The common theme, from an economic perspective, is the ability of all of these agents to reduce the rate of hospitalisation for worsening $\mathrm{HF}$, which is the major driver of the cost of this condition to health services and payers. Indeed, the reduction is so substantial that the cost savings either largely balance or even eliminate the additional costs of treatment (drug and monitoring) and increased longevity (ie, surviving patients require treatment, including procedures, and remain at risk of hospitalisation). Although we did not analyse the costeffectiveness of eplerenone in other European countries, previous studies with other effective treatments in HF have shown consistent findings in a variety of countries including Germany and France and there is no reason to believe that eplerenone would be different. ${ }^{17}$

When considering the results from a computer simulation model, it is ideal to be able to validate the clinical outcomes against empirical data. Unsurprisingly, the model accurately projects the within-trial outcomes (see online supplementary appendix). For the time beyond the trial follow-up period, the model also provides a reasonable approximation of current survival estimates for chronic systolic HF patients, with a mean survival of approximately 8 years in the standard care arm. ${ }^{3}$ Within-trial analysis, for which we have complete certainty in outcomes, estimated ICERs below the WTP thresholds for both the UK and Spain.

The much less expensive MRA spironolactone is approved for the treatment of patients with chronic systolic HF and moderate to severe symptoms (NYHA class III and IV), based upon the results of the RALES trial. ${ }^{6}$ It is not known whether the spironolactone would have had the same clinical effects 
(and therefore economic consequences) as eplerenone in EMPHASIS-HF. Eplerenone is a selective MRA whereas spironolactone is non-selective and the two agents have different tolerability profiles. ${ }^{19}$ Poorer tolerability and persistence of spironolactone could result in additional costs that may affect the difference in drug costs. ${ }^{19}$

\section{LIMITATIONS}

Although the model has been shown to produce clinically realistic projections, there are a number of limitations with this work that should be noted. First, this is a modelling study and does not represent empirically collected resource and quality-of-life outcomes associated with clinical findings. However, in the absence of more detailed data from the trial, a computer simulation such as this represents the next best solution. Second, as the EMPHASIS-HF trial was stopped early, due to early benefit in the eplerenone-treated group compared with the standard care arm, there is some uncertainty regarding the long-term outcomes of eplerenone in the available clinical data. Truncation issues are particularly likely to impact the absolute cost estimates for symptomatic decline (eg, device use) as outcomes are modelled based on projections from limited data. Truncated trials often associated with greater effect sizes, with moderate overestimation in trials such as EMPHASIS-HF where more than 500 events were observed. ${ }^{20}$ Uncertainty around the data has, however, been included within the modelling approach used and examined within both probabilistic and deterministic sensitivity analyses. The extent to which EMPHASIS-HF can be generalised is also limited by design features and other characteristics of the patients enrolled, including the tendency for trial patients to be younger and have less comorbidity than 'real-world' patients. The model did not take account of indirect costs, such as loss of earnings and pension payments to survivors, or other costs such as those related to admission to nursing homes. ${ }^{21} 22$

\section{Key messages}

\section{What is known on this subject?}

Addition of a mineralocorticoid receptor antagonist to treatment with an ACE inhibitor (or angiotensin receptor blocker) and b-blocker in patients with chronic systolic heart failure (HF) and mild symptoms reduced the risk of death and hospital admission in the Eplerenone in Mild patients Hospitalization and Survival Study in Heart Failure (EMPHASIS-HF), but the cost-effectiveness of this extra treatment is not known.

\section{What might this study add?}

Using a computer simulation model based on the outcomes of EMPHASIS-HF to replicate the trial outcomes, extrapolate these over a patient's lifetime and capture resource and health-related quality-of-life (utility) consequences produced incremental cost-effectiveness ratios (ICERs) of $£ 3520$ per quality-adjusted life year (QALY) for the UK and $€ 5532$ for Spain. These ICERs were well within the willingness-to-pay thresholds of $£ 20000$ per QALY (UK) or $€ 30000$ per QALY (Spain).

\section{How might this impact on clinical practice?}

The ICERs for eplerenone based upon EMPHAISIS-HF indicate that eplerenone is cost-effective as well as clinically effective.

\section{CONCLUSIONS}

The addition of eplerenone to standard therapy (with an ACE inhibitor and $\beta$-blocker) reduces the risk of all-cause mortality and all-cause hospitalisation in patients with chronic systolic HF and mild symptoms (NYHA class II). These clinical benefits offset a substantial portion of the additional drug cost associated with eplerenone, yielding favourable cost-effectiveness ratios well below standard WTP thresholds in the two European countries studied. Overall, this economic evaluation supports the use of eplerenone as a cost-effective treatment in eligible patients with chronic systolic HF and mild symptoms.

\section{Author affiliations}

${ }^{1}$ BresMed, Sheffield, UK

${ }^{2}$ Health Economic and Outcomes Research, Pfizer Ltd, Surrey, UK

${ }^{3}$ National Heart and Lung Institute, Imperial College (Royal Brompton Hospital) London, London, UK

${ }^{4} \mathrm{CHU}$ and Department of Cardiology, Inserm, Centre d'Investigation Clinique CIC 9501 and U961, Nancy University, Nancy, France

${ }^{5}$ Department of Epidemiology and Preventive Medicine, Centre of Cardiovascular Research and Education in Therapeutics, Monash University, Melbourne, Australia ${ }^{6}$ Department of Cardiology, Thorax Centre, University Medical Centre, Groningen, The Netherlands

${ }^{7}$ Pfizer, Inc., New York, USA

${ }^{8}$ University of Michigan School of Medicine, Ann Arbor, Michigan, USA

${ }^{9}$ The British Heart Foundation Cardiovascular Research Centre, University of Glasgow, Glasgow, UK

Acknowledgements Whitney Miller, Apostolos Charos and Javier Soto Rejas for providing local cost data.

Funding The EMPHASIS-HF study was sponsored by Pfizer.

Competing interests DL and RA are employees of BresMed and were paid consultants to Pfizer in connection with the development of this manuscript. MRC received an honorarium and travel expenses from Pfizer for advice in connection with the development of the health economic model and lecturing at medical educational events. KW and JV are employees of Pfizer and hold Pfizer Inc shares. FZ, HK, DJVV, BP and JJVM received remuneration from Pfizer for their services as a member of the Steering Committee for EMPHASIS-HF. BresMed conducted a results verification analysis, and this analysis was paid for by Pfizer Inc

Provenance and peer review Not commissioned; externally peer reviewed.

Open Access This is an Open Access article distributed in accordance with the Creative Commons Attribution Non Commercial (CC BY-NC 3.0) license, which permits others to distribute, remix, adapt, build upon this work non-commercially, and license their derivative works on different terms, provided the original work is properly cited and the use is non-commercial. See: http://creativecommons.org/ licenses/by-nc/3.0/

\section{REFERENCES}

1 National Institute for Cardiovascular Outcomes Research. National heart failure audit: April 2010—march 2011. http://www.ucl.ac.uk/nicor/audits/heartfailure/ (accessed 1 May 2013).

2 Mosterd A, Hoes AW. Clinical epidemiology of heart failure. Heart 2007;93:1137-46.

3 Cowie MR, Wood DA, Coats AJS, et al. Survival of patients with a new diagnosis of heart failure: A population based study. Heart 2000;83:505-10.

4 Stewart S, Maclntyre K, Hole DJ, et al. More 'malignant' than cancer? Five-year survival following a first admission for heart failure. Eur J Heart Fail 2001;3:315-22.

5 McMurray JJV, Adamopoulos S, Anker SD, et al. Esc guidelines for the diagnosis and treatment of acute and chronic heart failure 2012. Eur Heart J 2012;33:1787-847.

6 Pitt B, Zannad F, Remme WJ, et al. The effect of spironolactone on morbitity and mortality in patients with severe heart faliure. N Engl J Med 1999:341:709-17.

7 Zannad F, McMurray JJ, Krum H, et al. Eplerenone in patients with systolic heart failure and mild symptoms. N Engl J Med 2011;364:11-21.

8 Pitt B, Remme W, Zannad F, et al. Eplerenone, a selective aldosterone blocker, in patients with left ventricular dysfunction after myocardial infarction. N Engl J Med 2003:348:1309-21.

9 Caro JJ, Möller J, Getsios D. Discrete event simulation: The preferred technique for health economic evaluations? Value Health 2010;13:1056-60.

10 Preiss D, van Veldhuisen DJ, Sattar N, et al. Eplerenone and new-onset diabetes in patients with mild heart failure: Results from the eplerenone in mild patients 
hospitalization and survival study in heart failure (emphasis-hf). Eur J Heart Fail 2012;14:909-15.

11 Fox M, Mealing S, Anderson R, et al. The clinical effectiveness and cost-effectiveness of cardiac resynchronisation (biventricular pacing) for heart failure: Systematic review and economic model. Health Technol Assess 2007:11:iii-iv, ix-248.

12 Harrell F. Regression modeling strategies: With applications to linear models, logistic regression, and survival analysis. Springer, 2001.

13 Rogers JK, McMurray JJ, Pocock SJ, et al. Eplerenone in patients with systolic heart failure and mild symptoms: Analysis of repeat hospitalizations. Circulation 2012;126:2317-23.

14 Göhler A, Geisler BP, Manne JM, et al. Utility estimates for decision-analytic modeling in chronic heart failure - health states based on new york heart association classes and number of rehospitalizations. Value Health 2009;12:185-7.

15 Hart W, Rhodes G, McMurray J. The cost effectiveness of enalapril in the treatment of chronic heart failure. Br J Med Econ 1993:6:91-8.

16 McMurray JJ, Andersson FL, Stewart S, et al. Resource utilization and costs in the candesartan in heart failure: Assessment of reduction in mortality and morbidity (charm) programme. Eur Heart J 2006;27:1447-58.

17 Stewart S, McMurray JJ, Hebborn A, et al. Carvedilol reduces the costs of medical care in severe heart failure: an economic analysis of the copernicus study applied to the united kingdom. Int J Cardiol 2005;100:143-9.

18 Bacquet $\mathrm{P}$, Levy E, McGuire A, et al. Reduced costs with bisoprolol treatment for heart failure: An economic analysis of the second cardiac insufficiency bisoprolol study (cibis-ii). Eur Heart J 2001;22:1021-31.

19 Sullivan PW, Slejko JF, Sculpher MJ, et al. Catalogue of eq-5d scores for the united kingdom. Med Decis Making 2011:31:800-4.
20 Bassler D, Briel M, Montori VM, et al. Stopping randomized trials early for benefit and estimation of treatment effects: Systematic review and meta-regression analysis. JAMA 2010:303:1180-7.

21 Stewart S, Jenkins $A$, Buchan $S$, et al. The current cost of heart failure to the national health service in the uk. Eur J Heart Fail 2002:4:361-71.

22 Stewart S, Blue L, Walker A, et al. An economic analysis of specialist heart failure nurse management in the UK; can we afford not to implement it? Eur Heart J 2002:23:1369-78.

23 Joint Formulary Committee. British National Formulary 62. London: BMJ Group and Pharmaceutical Press. http://www.medicinescomplete.com (accessed 1 May 2013).

24 Cataolgo de especialidades farmaceuticas. Madrid: Consejo General de Colegios Oficiales de Farmaceuticos, 2011.

25 Oblikue Consulting. Base de conocimiento de costes y precios del sector sanitario http://oblikue.com/bddcostes/ (accessed September 2011).

26 Curtis L. Unit costs of health and social care 2011. http://www.pssru.ac.uk/pdf/uc/ uc2011/uc2011.pdf (accessed 1 May 2013).

27 Scotland ISD. 2010/11 scottish tariffs for cross boundary flow costing. http://www. isdscotland.org/Health-Topics/Finance/Scottish-National-Tariff/1011ScotTariffs.xls? 76638430357-2011-05-09 (accessed 1 May 2013).

28 Berg J, Lindgren P, Nieuwlaat R, et al. Factors determining utility measured with the eq-5d in patients with atrial fibrillation. Qual Life Res 2010;19:381-90.

29 Mowatt G, Vale L, Perez J, et al. Systematic review of the effectiveness and cost-effectiveness of home versus hospital or satellite unit haemodialysis for people with end stage renal failure. (accessed 1 May 2013). 